\title{
Quantitative Assessment of Contractile Reserve of Systemic Right Ventricle in Post-Senning Children: Incorporating Speckle-tracking Strain and Dobutamine Stress Echocardiography
}

\author{
Fatma Taha ${ }^{1}$, Sahar Elshedoudy ${ }^{1}$, and Mona Adel ${ }^{1}$ \\ ${ }^{1}$ Tanta University Faculty of Medicine
}

June 28, 2020

\begin{abstract}
Introduction: The systemic load on the right ventricle (RV) after Senning atrial switch leads to ventricular dysfunction. Quantitative assessment of RV contractile reserve is mandatory to anticipate the need for anti-failure treatment. We aimed to quantitatively assess RV contractile reserve in Senning children by interrogating speckled global longitudinal strain (GLS) during dobutamine stress echocardiography (DSE). Methods: This prospective study compared thirty-one post-Senning children (group I), and thirty controls (group II). In post-Senning children, echocardiographic RV systolic function using automated Simpson's one-plane ejection fraction (RVEF), tricuspid annulus plane systolic excursion (TAPSE), and RVGLS were recorded at rest and at peak DSE. The contractile reserve was defined as improvement $>5 \%$ in RVEF, $>2 \%$ in GLS, and/or to near normal values in TAPSE. Results: RVEF, and TAPSE were significantly lower in patients than controls (RVEF: $40.13 \pm 2.93 \%$ vs. $53.17 \pm 3.17 \%$ respectively, $\mathrm{P}<0.001 *$, TAPSE: $13.81 \pm 1.26$ vs. $17.45 \pm 2.93 \mathrm{~mm}$ respectively, $\mathrm{P}<0.001 *)$. Also, RVGLS was significantly worse in Senning children than controls $\left(-11.89 \pm 2.31 \%\right.$ vs. $-22.35 \pm 6.73 \%$ respectively, $\left.\mathrm{P}<0.001^{*}\right)$. At peak DSE, contractile reserve was not evident as measured by RVEF which increased none significantly to $42.47 \pm 2.80 \%$ ( $\mathrm{P}=0.063)$. However, RVGLS improved significantly to $-15.78 \pm 0.93 \%\left(\mathrm{P}<0.001^{*}\right)$ and discovered the masked contractile reserve in Senning children. The 19(61.29\%) children who showed masked contractile reserve (improvement in RVGLS $>2 \%$ ) underwent continuation of antifailure medications. Conclusions: Despite systemic RV function in post-Senning children was impaired at rest and during DSE, RVGLS was useful in quantitative assessment of masked contractile reserve that was not evaluated by the ordinary RVEF, thus promoted continuing anti-failure treatment.
\end{abstract}

\section{TEXT:}

\section{INTRODUCTION:}

In patients who underwent an atrial switch repair (Mustard or Senning procedures) (1) for complete transposition of the great arteries (D-TGA), the morphological right ventricle (RV) acts as a systemic ventricle and the systemic atrioventricular (AV) valve is anatomically the tricuspid valve (TV). Chronic systemic pressure load on the RV might lead to ventricular dysfunction, progressive tricuspid regurge (TR), and heart failure (HF). (2) In patients who underwent atrial switch repair, the systemic ventricular function is an independent predictor of exercise capacity. Therefore, atrial switch operations are accompanied by increased morbidity and delayed mortality, mainly because of heart failure (3) and ventricular tachycardia due to dysfunction of the systemic RV (4). In these patients, RV function deterioration is a progressive and accumulating condition. (5) So, accurate assessment of RV function and the contractile reserve is mandatory to anticipate the need for heart failure treatment in these patients.

The systemic RV function can be assessed by several imaging modalities including angiography, radionuclide imaging, and magnetic resonance imaging (). (6) However, echocardiography is still used predominantly for the assessment of RV function, as it is noninvasive, applicable, available, and inexpensive modality. 
Theoretically, stress echocardiography (SE) may deliver more information about the myocardial contractile reserve, and the behavior of the TR during stress. Myocardial contractile reserve measured by stress testing has been defined as the difference of ventricular function at rest and under loading conditions. As, Dobutamine acts directly and mostly on b-1 adrenergic receptors of the myocardium, producing an increase in heart rate and contractility, dobutamine stress echocardiography (DSE) can assess contractile reserve in such patients. (8)

RV has a complex geometry, so, the assessment of systemic RV function and RV contractile reserve by echocardiography is better to be based on quantitative assessment. Two-dimensional (2D) speckle tracking echocardiography () has established as a valuable tool to assess global and regional myocardial deformation. $(9,10)$ 2D Myocardial speckle tracking strain (S) is a consistent Doppler and angle independent technique that quantitatively measures ventricular geometry and systemic RV myocardial dysfunction. (11-14)

To redefine the role of echocardiography in the functional assessment of systemic right ventricular contractile reserve in post-Senning children, we aimed to quantitatively assess the systemic RV contractile reserve in such patients by interrogating speckle-tracking based global longitudinal strain (GLS) measurement during Dobutamine Stress Echocardiography (DSE).

\section{METHODS:}

\section{Patients:}

This prospective controlled study took place starting from May 2017 to December 2019. The study was approved by the institutional human research ethics committee, and the study protocol obeys to the ethical guidelines of the 1975 Declaration of Helsinki, and its ethical standards. Informed consent was obtained from the patient guardian. The study enrolled two groups; group I thirty-one children with complete TGA (D-TGA) who had undergone atrial redirection by the Senning procedure, who are $<14$ years age, and who had been clinically stable for at least 3 months, and group II, thirty age- and weight-matched control children.

All the studied children were subjected to clinical evaluation including; the presenting symptoms, the oxygen saturation, the heart rate, the blood pressure, the N-terminal (NT)-pro hormone BNP (NT-proBNP), the electrocardiography and the echocardiographic Doppler assessment of systemic RV systolic function using standard ultrasound parameters and 2D speckle tracking strain curves at rest and high dose dobutamine stress echocardiography.

\section{Standard echocardiography:}

All patients underwent complete transthoracic echocardiographic examination according to the American Society of Echocardiography (ASE) guidelines (15) using an ultrasound system; the General Electric (GE) VIVID 9 ultrasound (Horten, Norway) equipped with a multi-frequency transducer probe (3-8 MHz). The echocardiographic examination was done at rest and children who were unable to completely rest during imaging were given light sedation. Measurements were taken in three cardiac cycles and average values were estimated offline and were used for statistical analyses. Intra- and inter-observer variability was studied based on two consecutive results.

Usual examination for Senning patients was done taking into consideration the systemic tricuspid valve regurgitation, the pulmonary and systemic venous baffles dysfunction (Leak or stenosis), the outflow tracts (the left ventricular outflow tract obstruction (LVOT), and the pulmonary valve dysfunction).

Common echocardiographic variables for RV function; RV end-diastolic volume (RV EDV), RV end-systolic volume (RV ESV), and RV ejection fraction (RV EF) were estimated in the apical four-chamber view, using the automated Simpson's one-plane method. RV EF was assessed automatically by dividing RV EDV - RV ESV / RV EDV. (16) Right ventricular tricuspid annulus plane systolic excursion (TAPSE) was estimated as the amplitude of excursion of the tricuspid annulus from the base toward the apex in systole using M-mode in the apical four-chamber view with cursor was sited at the lateral aspect of the tricuspid valve. 
Two-dimensional (2D) Speckle tracking strain curve:

Myocardial deformation imaging by two-dimensional (2D) strain based on speckle tracking deformation imaging, as an index of contractile function, was assessed on grey-scale echocardiographic images. (17) Electrocardiogram was contacted to the patient's chest till proper adjustment of the heart rate recording on the echocardiography machine. A frame rate of 80-100 frames/sec was utilized for storage and analysis. At least three consecutive cardiac cycles of $2 \mathrm{D}$ apical four-chamber images were documented at each plane and were introduced into the GE Echo-PAC (BT 09, Horten, Norway) workstation to select the best Speckle tracking analysis images. The images were optimized to visualize the myocardial walls. 2D speckle tracking offline analysis software was automatically tracked the endocardial, epicardial borders and the myocardial movement of the RV frame by frame, thus delineating a region of interest composed of six segments including (Basal-lateral, mid-lateral, apico-lateral, apico-septal, mid-septal and basal-septal). The analysis was established when adequate tracking was confirmed by visual inspection and the software. If the tracking of the RV endocardium was unsatisfactory, manual adjustments of the region of interest size were achieved to confirm optimal tracking. RV systolic strain curves were assessed in the longitudinal direction for each segment by the software. Once approved, the software displayed an average which is the global longitudinal strain (GLS) to assess the global RV myocardial function automatically. (18-20) These echocardiographic measures were recorded and reported at rest and after dobutamine stress.

Dobutamine stress echocardiography (DSE):

After six hours fasting, the dobutamine stress test was used to assess all echocardiographic parameters after dobutamine infusion [Started at $2.5 \mu \mathrm{g} / \mathrm{kg} / \mathrm{min}$, and increased gradually every $3 \mathrm{~min}$ and maximally to $40 \mu \mathrm{g} / \mathrm{kg} / \mathrm{min}$ (Atropine was not given as it was unsafe and probably unnecessary in such age group)]. Dobutamine stress endpoints were taken with reaching the predicted target heart rate for age [85\% (220 minus age in years)], starting symptoms (Dyspnea and or arrhythmia), or reaching $40 \mu \mathrm{g} / \mathrm{kg} / \mathrm{min}$ dobutamine dose. Heart rate and blood pressure were recorded at every stage. Baseline and peak dose images were stored and compared offline. (8)

A normal response to dobutamine infusion was demarcated as a progressive increase in myocardial thickening and hyperdynamic wall motion as assessed by RV EF, RV GLS, and TAPSE from rest to peak dose dobutamine infusion (negative DSE). An abnormal response to dobutamine infusion was clarified as a reduction in myocardial thickening or wall motion at any stage of the dobutamine infusion compared with the previous stage (positive DSE). (8) Global contractile reserve was defined as improvement $>5 \%$ in RV EF, $>2 \%$ in RV GLS, and/or to near normal parameter $\mathrm{Z}$ values in TAPSE. (8) Any change in cardiac function (improvement or worsening in RV EF, RV GLS, TAPSE), LVOT gradients, and severity of TR was reported.

\section{Statistical analysis:}

Statistical analysis was approved with the SPSS statistical package (Version 25; SPSS Inc., Chicago, IL, USA). Quantitative data were stated as mean \pm standard deviation (SD), and Qualitative data were displayed using numbers and percentages. The Kolmogorov-Smirnov test was used to confirm the normality of distribution. Comparative data between the two groups, the Senning patients and the controls were assessed using the unpaired t-test. Changes in hemodynamic and echocardiographic parameters between rest and dobutamine stress were compared using a paired Student t-test. A P-value $<0.05$ was considered statistically significant at a confidence interval of $95 \%$.

\section{RESULTS}

\section{Demographic and clinical characteristics:}

In this study; group I Senning patients included $20(62.52 \%)$ boys and $11(35.48 \%)$ girls, with a mean age of $12.88 \pm 3.12$ years, and mean weight of $31.71 \pm 9.17 \mathrm{Kg}$, while, group II controls included $15(50.00 \%)$ boys and $15(50.00 \%)$ girls, with a mean age of $12.50 \pm 2.92$ years, and mean weight of $33.18 \pm 8.96 \mathrm{Kg}$. In the Senning patient group, the mean patients' age at Senning operation was $11.2 \pm 1.30$ months, and 9 (29.03 $\%)$ patients had associated ventricular septal defect (VSD) and were therefore referred to as 'complex TGA; 
in these patients, the VSDs were closed at the time of the atrial redirection surgeries, without residual leaks. From the 31 Senning group; 9 (29.03\%) patients presented with dyspnea grade II-IV, 3 (9.68 \%) patients presented with chest infection, and no patients exhibited arrhythmias.

As regard to hemodynamic data; oxygen saturation was significantly lower in Senning patients than controls $\left(97.75 \pm 0.50 \%\right.$ vs. $99.15 \pm 0.76 \%$ for group I and group II respectively, $\left.\mathrm{P}=0.04^{*}\right)$, and heart rate was significantly higher in Senning patients than controls $(98.45 \pm 15.76 \mathrm{bpm}$ vs. $89.31 \pm 10.17 \mathrm{bpm}$ for the group I and group II respectively, $\mathrm{P}=0.01 *)$. However, there was no significant difference between Senning group and control group in blood pressure measurements $(105.85 \pm 13.31 / 71.75 \pm 11.41 \mathrm{mmHg}$ vs. $107.50 \pm$ $14.55 / 72.00 \pm 10.24 \mathrm{mmHg}$ for the group I and group II respectively, $\mathrm{P}=0.26)$.

Pro-BNP was significantly higher in Senning patients than controls $(531.54 \pm 45.33 \mathrm{ng} / \mathrm{L}$ vs $115 \pm 13.62$ $\mathrm{ng} / \mathrm{L}$ respectively, $\left.\mathrm{P}<0.001^{*}\right)$.

Echocardiographic results at rest:

Tricuspid systemic atrioventricular valve regurge was evident in all cases; however, it was mild in 18 (58.06 \%) patients, moderate in $9(29.03 \%)$ patients, and severe in $4(12.90 \%)$ patients. Baffle leak was evident in two $(6.45 \%)$ patients and no pulmonary or systemic baffle stenosis was recorded in any of the patients.

RV EDV and RV ESV were significantly higher in Senning patients than in controls; RV EDV was 53.95 $\pm 10.31 \mathrm{ml}$ in the patient group vs. $43.63 \pm 3.87 \mathrm{ml}$ in the control group $\left(\mathrm{P}=0.002^{*}\right)$, and RV ESV was $32.15 \pm 9.70 \mathrm{ml}$ in the patient group vs. $26.63 \pm 5.11 \mathrm{ml}$ in the control group $\left(\mathrm{P}=0.015^{*}\right)$. Overall RV EF assessed using Simpson's method echocardiography was significantly diminished in the patient group than the controls; $40.13 \pm 2.93 \%$ vs. $53.17 \pm 3.17 \%$ respectively, $\mathrm{P}<0.001 *$ TAPSE was significantly reduced in group I Senning patients than group II controls; $13.81 \pm 1.26 \mathrm{~mm}$ vs. $17.45 \pm 2.93 \mathrm{~mm}$ respectively $\left(\mathrm{P}<0.001^{*}\right)$. 2D right ventricular global longitudinal strain (RV GLS) was significantly worse in group I Senning patients than group II controls; $-11.89 \pm 2.31 \%$ vs. $-22.35 \pm 6.73 \%$ respectively $\left(\mathrm{P}<0.001^{*}\right)$. Demographic, clinical, and echocardiographic data of the studied groups are shown in table (1).

Peak dobutamine stress echocardiography (DSE):

At peak DSE, 17 (54.84 \%) patients developed dyspnea and were in New York Heart Association (NYHA) function class II/III. Only, two $(6.45 \%)$ patients developed arrhythmias in the form of infrequent atrial ectopics.

There was no significant decrease in oxygen saturation from $97.75 \pm 1.50 \%$ at rest to $96.25 \pm 1.41 \%$ at peak DSE $(\mathrm{P}=0.07)$. Despite, heart rate increased significantly from $98.45 \pm 15.76 \mathrm{bpm}$ at rest to 121.50 $\pm 17.20 \mathrm{bpm}$ at peak stress $\left(\mathrm{P}=0.021^{*}\right)$, the patient showed chronotropic incompetence as $12(38.721 \%)$ patients did not reach the expected target heart rate for age at peak stress (173.56 - $178.77 \mathrm{bpm})$, and 19 (61.29\%) patients underwent immediate dobutamine withhold due to appearing of symptoms (dyspnea or arrhythmia) during the examination. Blood pressure increased significantly from $106.50 \pm 13.09$ / $72.50 \pm$ $10.24 \mathrm{mmHg}$ at rest to $132.25 \pm 13.03 / 82.50 \pm 12.51 \mathrm{mmHg}$ at peak stress $\left(\mathrm{P}=0.042^{*}\right)$.

With peak DSE, no patients developed pulmonary or systemic baffle stenosis or obstruction in the LVOT. Tricuspid systemic valve regurge was more apparent post-stress to be; mild only in $11(35.48 \%)$ patients, moderate in $15(48.39 \%)$ patients, and severe in $5(16.13 \%)$ patients.

Despite RV EDV showed no significant decrease from $53.95 \pm 10.31 \mathrm{ml}$ at rest to $50.25 \pm 8.84 \mathrm{ml}$ at peak stress $(\mathrm{P}=0.31)$, RV ESV significantly decreased from $32.15 \pm 9.70 \mathrm{ml}$ at rest to $30.35 \pm 9.50 \mathrm{ml}$ at peak stress $\left(\mathrm{P}=0.010^{*}\right)$.

The contractile reserve was not evident as measured by RV EF that increased but non significantly from $40.13 \pm 2.93 \%$ at rest to $42.47 \pm 2.80 \%$ at peak stress $(\mathrm{P}=0.063)$, with $<5 \%$ improvement in RV EF. Figure (1) showed a non-significant $(<5 \%)$ increase in RV EF by Simpson's method in a post-Senning 13 years old child from $39 \%$ at rest to $42 \%$ at peak stress Echocardiography. 
However TAPSE and RV GLS showed that there is still a contractile reserve in Senning patients in the childhood age; TAPSE increased significantly from $13.81 \pm 1.26 \mathrm{~mm}$ basally to $15.34 \pm 2.61 \mathrm{~mm}$ at peak stress $\left(\mathrm{P}=0.003^{*}\right)$, and RV GLS improved significantly $>-2 \%$ from $-11.89 \pm 1.31 \%$ basally to $-15.78 \pm$ $0.93 \%$ at peak stress $\left(\mathrm{P}<0.001^{*}\right)$. Dobutamine stress echocardiography and contractile reserve in Senning patients were shown in table (2). Figure (2) showed the quantitatively assessed contractile reserve in a Senning patient child of 11 years old with an improvement of RV GLS from $-11.2 \%$ at rest to $-15.6 \%$ at peak dobutamine stress Echocardiography.

$19(61.29 \%)$ patients showed masked RV contractile reserve with $>2 \%$ improvement in RV GLS despite $<$ $5 \%$ improvement in RV EF. These patients underwent anti-fibrotic and anti-failure medications in the form of angiotensin-converting enzyme inhibitors/ angiotensin receptor blockers (ACEI/ARBs), spironolactone therapy, and sometimes beta-blockers (In patients without symptoms of heart failure).

\section{DISCUSSION:}

\section{Resting echocardiography:}

In patients with D-TGA who underwent atrial switch repair, there are several potential mechanisms for TV regurgitation including, congenital abnormalities of the TV, dysfunction of the systemic RV, right-to-left septal shift, increased retrograde trans-tricuspid pressure gradient, and iatrogenic causes. (21) In this study, TV regurgitation was related to RV enlargement and dysfunction rather than related to anomalies of the TV. It is still not clear whether systemic RV dysfunction or TV regurgitation occurs first. (22)

Patients with systemic RV post atrial switch surgery also have preload abnormalities, and such factors should be taken into account. After a Senning operation, patients may develop hemodynamic abnormalities related to pulmonary and systemic baffles. (23) After the atrial switch, echocardiography is recommended for the evaluation of the systemic right ventricle and integrity of the baffle. (24) In our study, we observed no baffle narrowing with only small baffle leaks in 2 patients denoting preload impairment on the systemic ventricle in these two patients.

The improvement in survival of patients after D-TGA surgical correction (particularly in patients with atrial switch and systemic RV) result in the development of late complications, commonly in adulthood, such as heart failure, atrial arrhythmias, and sudden cardiac death, the incidence of which increases over time. Watchful follow-up is necessary and serial imaging is required to analyze changes in systolic function over time. After atrial switch repair, right ventricular dysfunction was recorded in $48 \%$ of patients with D-TGA, symptomatic heart failure was reported in $25 \%$ at 15 to 18 years of follow-up, and more than $50 \%$ had moderate to severe systemic right ventricular dysfunction after 25 years. $(5,25,26)$

In this study systemic RV function was significantly depressed in the atrial switch Senning children than in the controls as measured by echocardiographic parameters; RV EF by Simpson's one-plane method, TAPSE, and speckled RV GLS. This was in agreement with some investigators $(27,28)$ who have proposed that myocardial fibrosis results from prolonged hypoxemia during infancy while patients await the atrial switch repair. Others (29) have believed that it may be caused by insufficient RV blood supply from the right coronary artery in the presence of hypertrophic systemic RV myocardium. These conditions are similar to the morphologic and hemodynamic changes of the RV in pulmonary artery hypertension patients in which afterload is also augmented. (30) Others denoted the presence of the atrial baffles (even those that are well functioning) may decrease RV inflow and consequently RV function. (23)

In patients with structurally normal hearts, the traditional approach to the assessment of systemic ventricular function is to measure ejection fraction. However, attempting to extend this to the atrial switch situation has proved challenging. The geometry of the RV makes it difficult to measure ejection fraction by echocardiography, which has prompted simple visual estimation. In contrast, with the introduction of 2D speckle tracking echocardiography, simple measurement of long-axis GLS is a rapid and definite measurement that has proven utility in a thorough assessment of subtle dysfunction at the early stage, but it has not been definitively estimated in patients with TGA. The technique is equally straightforward for the RV and 
is especially valid because the main bulk of right ventricular myocardial fibers are arranged longitudinally. With this technology, dysfunction can also be assessed online with very short processing times.

A correlation between Cardiac MRI-derived right ventricular function and right ventricular GLS has been described previously by Lipczynska et al. (31) In their prospective study of 40 patients with D-TGA after the atrial switch procedure (mean age $26 \pm 5$ years), they found a significant linear correlation between the systemic RV EF by cardiac MRI and RV GLS by echocardiography. In the mentioned study, systemic right ventricular GLS was proposed to be able to discriminate between systemic RV EF below or above $45 \%$ derived from cardiac MRI. However cardiac MRI has some limitations for its application in clinical practice including restricted availability, high cost, and contraindications, particularly for serial long-term follow-up of these patients. (32)

The Speckled RV GLS data in our current study confirm reduced systolic contractile function in the systemic RV of Senning children as compared to similar age controls. It has been suggested that systemic right ventricular GLS in patients with systemic right ventricular dysfunction has been found to have a high predictive value, high reproducibility, and can predict adverse clinical outcomes as morbidity and mortality. (33) A reduced septal longitudinal strain may contribute to reduced septal work and failure of the systemic right ventricle in TGA patients. (33)

\section{Dobutamine Stress Echocardiography:}

In this study, Senning patients showed chronotropic incompetence, as the increase in heart rate at peak stress did not reach the expected target heart rate for age or the test had been aborted because of the development of symptoms (Dyspnea, or arrhythmia). Chronotropic incompetence may be the cause of dyspnea in such patients during dobutamine infusion. This was in agreement with Sterrett LE et al, who noticed that decreased exercise tolerance in patients after arterial switch surgery for D-transposition of the great arteries was due to chronotropic incompetence and was known to be associated with increased mortality in adults. $(34)$

In this study the tricuspid systemic atrioventricular regurge increased in severity with peak dobutamine stress, this may be because the decrease in RV EDV was non-significant that remained tricuspid valve annulus dilated with increased contractility on the other hand during peak dobutamine stress.

In this study, despite, the dysfunctional RV showed an increase in RV EF with peak dose stress dobutamine, but this increase was not that such a significant one. This may be due to the significant decrease in RV end-systolic volume than RV end-diastolic volume. So, wall stress increased less with dobutamine stress test in patients who underwent the Senning procedure. However, in this study other parameters used to assess the contractile reserve of the systemic RV; TAPSE, and RV GLS proved the existence of masked RV contractile reserve at peak dobutamine stress echocardiography in such age group of Senning patients, thus promoting the necessity for continuing anti-fibrotic and anti-failure measures in those patients in such age group. Monitoring exercise capacity, contractile reserve, and response to anti-fibrotic measures in atrial switch patients remain important diagnostic and predictive tests.

\section{Study limitations:}

We cannot compare Senning patients group with controls at peak dobutamine stress, because control children had not indications for the dobutamine stress test, with the high risk on them that was against the ethical committee guidelines. This problem can be solved later on in their adult life, as we will continue studying those patients and we will compare them with adult controls who will be subjected to Dobutamine stress echocardiography for any other reasons. A larger series of patients and longer follow-up times are needed to establish the safety of various stressors in these populations.

\section{CONCLUSIONS:}

Systemic right ventricular function in patients with Senning repair was impaired at rest and during dobutamine stress echocardiography (even among asymptomatic ones) and appears to limit exercise capacity 
(symptom appearance), chronotropic incompetence, and increase in the severity of TV regurgitation. Right ventricular 2D echocardiography speckle tracking based global longitudinal strain (GLS) was a feasible, easy, and useful parameter in the quantitative assessment of systemic RV function in patients with Senning operation. In the children's age group with Senning repair at peak dose DSE, the speckle based RV GLS accurately and quantitatively assessed the masked contractile reserve that was not evaluated by the ordinary volume estimation and RV ejection fraction (RV EF) methods. Despite the significant improvement in RV GLS, it did not reach the expected normal values, but it still helped estimate the masked contractile reserve thus promoted continuing cardiac anti-fibrotic treatment in these patients. Still, these children after atrial switch repair need serial long-term follow-up monitoring.

\section{AUTHOR CONTRIBUTIONS}

- Fatma Aboalsoud Taha; MD: Design, data analysis/interpretation, drafting article, critical revision of the article, approval of the article, statistics, and data collection.

- Sahar Elshedoudy; MD: Concept, data analysis/interpretation, critical revision of the article, approval of the article, and statistics.

- Mona Adel; MD: Data analysis/interpretation, critical revision of the article, and approval of the article.

\section{REFERENCES}

1. Senning A: Surgical correction of transposition of the great vessels. Surgery 1959:45:966-980.

2. Budts W, Scheurwegs C, Stevens A, et al: The future of adult patients after mustard or senning repair for transposition of the great arteries. Int J Cardiol 2006:113:209-214.

3. Piran S, Veldtman G, Siu S, et al: Heart failure and ventricular dysfunction in patients with single or systemic right ventricles. Circulation 2002:105:1189-1194.

4. Moons P, Gewillig M, Sluysmans T, et al: Long term outcome up to 30 years after the Mustard or Senning operation: a nationwide multicenter study in Belgium. Heart 2004:90:307-313.

5. Roos-Hesselink JW, Meijboom FJ, Spitaels SE, et al: Decline in ventricular function and clinical condition after Mustard repair for transposition of the great arteries (a prospective study of 22-29 years). Eur Heart J 2004:25:1264-1270.

6. Sigal-Cinqualbre A, Lambert V, Ronhean A, et al: Role of MSCT and MRI in the diagnosis of congenital heart disease. Arch Pediatr 2011:18: 617-627

7. Li W, Hornung TS, Francis DP, et al: Relation of biventricular function quantified by stress echocardiography to cardiopulmonary exercise capacity in adults with mustard (atrial switch) procedure for transposition of the great arteries. Circulation 2004:110:1380-1386.

8. Lancellotti P, Pellikka PA, Budts W, et al: The Clinical Use of Stress Echocardiography in NonIschaemic Heart Disease: Recommendations from the European Association of Cardiovascular Imaging and the American Society of Echocardiography. Journal of the American Society of Echocardiography 2017:101-136.

9. Friedberg MK, Mertens L: Tissue velocities, strain, and strain rate for echocardiographic assessment of ventricular function in congenital heart disease. Eur J Echocardiogr 2009:10:585-593.

10. Chow PC, Liang XC, Cheung EW, et al: New two-dimensional global longitudinal strain and strain rate imaging for assessment of systemic right ventricular function. Heart 2008:94:855-9.

11. Pettersen E, Fredriksen PM, Urheim S, et al: Ventricular function in patients with transposition of the great arteries operated with arterial switch. Am J Cardiol 2009:104:583-589.

12. Knirsch W, Dodge-Khatami A, Kadner A, et al: Assessment of myocardial function in pediatric patients with operated tetralogy of Fallot: preliminary results with 2D strain echocardiography. Pediatr Cardiol 2008:29:718-725.

13. Perk G, Tunick PA, Kronzon I: Non-Doppler two-dimensional strain imaging by echocardiography From technical considerations to clinical applications. J Am Soc Echocardiogr 2007:20:234-243.

14. Bos JM, Hagler DJ, Silvilairat S, et al: Right ventricular function in asymptomatic individuals with a systemic right ventricle. J Am Soc Echocardiogr 2006:19:1033-1037. 
15. Lopez L, Colan SD, Frommelt PC, et al: Recommendations for quantification methods during the performance of a pediatric echocardiogram: a report from the Pediatric Measurements Writing Group of the American Society of Echocardiography Pediatric and Congenital Heart Disease Council. J Am Soc Echocardiogr 2010:23:465-495.

16. Davlouros PA, Niwa K, Webb G, et al: The right ventricle in congenital heart disease. Heart, 2006:92(1):27-38

17. Kalogeropoulos AP, Georgiopoulou VV, Giamouzis G, et al: Myocardial deformation imaging of the systemic right ventricle by two-dimensional strain echocardiography in patients with d-transposition of the great arteries. Hellenic J Cardiol 2009:50:275-282.

18. Vitarelli A, Sardella G, Roma AD, et al: Assessment of right ventricular function by three-dimensional echocardiography and myocardial strain imaging in adult atrial septal defect before and after percutaneous closure. Int J Cardiovasc Imaging 2012:28:1905-1916.

19. Voigt JU, Pedrizzetti G, Lysyansky P, et al: Definitions for a common standard for 2D speckle tracking echocardiography: consensus document of the EACVI/ASE/Industry Task Force to standardize deformation imaging. J Am Soc Echocardiogr 2015:28:183-193.

20. Aslan M, Erturk M, Turen S, et al: Effects of percutaneous closure of atrial septal defect on left atrial mechanical and conduction functions. Eur Heart J Cardiovasc Imaging 2014:15:1117-1124.

21. Szymanski P, Klisiewicz A, Lubiszewska B, et al: Factors associated with the presence of tricuspid valve regurgitation in patients with systemic right ventricles following atrial switch. Cardiol J 2010:17(1):2934.

22. Miltner B, Lancellotti P, Seghaye MC: European Society of Cardiology. European Society of Cardiology guidelines for the management of complex grown-up congenital heart disease [in French]. Rev Med Liege 2014:69(1):16-25.

23. Singh TP, Wolfe RR, Sullivan NM, et al: Assessment of progressive changes in exercise performance in patients with a systemic right ventricle following the atrial switch repair. Pediatr Cardiol 2001:22(3):210-214.

24. Stout KK, Broberg CS, Book WM, et al: Chronic heart failure in congenital heart disease. A scientific statement from the American Heart Association. Circulation 2016:133:770-801.

25. Kirjavainen M, Happonen JM, Louhimo I: Late results of Senning operation. J Thorac Cardiovasc Surg 1999:117:488-495.

26. Puley G, Siu S, Connelly M, et al: Arrhythmia and survival in patients $>18$ years of age after the Mustard procedure for complete transposition of the great arteries. Am J Cardiol 1999:83:1080-1084.

27. Winter MM, van der Plas MN, Bouma BJ, et al: Mechanisms for cardiac output augmentation in patients with a systemic right ventricle. Int J Cardiol 2010:143(2):141-146.

28. Plymen CM, Sado DM, Taylor AM, et al: Diffuse myocardial fibrosis in the systemic right ventricle of patients late after Mustard or Senning surgery: an equilibrium contrast cardiovascular magnetic resonance study. Eur Heart J Cardiovasc Imaging 2013:14 (10):963-968.

29. Hornung TS, Bernard EJ, Jaeggi ET, et al: Myocardial perfusion defects and associated systemic ventricular dysfunction in congenitally corrected transposition of the great arteries. Heart 1998:80 (4):322-326.

30. Naeije R, Manes A: The right ventricle in pulmonary arterial hypertension. Eur Respir Rev 2014:23(134):476-487.

31. Lipczynska M, Szymanski P, Kumor M, et al: Global longitudinal strain may identify preserved systolic function of the systemic right ventricle. Can J Cardiol. 2015:31(6):760-766.

32. Kilner PJ, Geva T, Kaemmerer H, et al: Recommendations for cardiovascular magnetic resonance in adults with congenital heart disease from the respective working groups of the European Society of Cardiology. Eur Heart J 2010:31:794-805.

33. Storsten P, Eriksen M, Remme EW, et al: Dysfunction of the systemic right ventricle after atrial switch: physiological implications of altered septal geometry and load. J Appl Physiol 2018:125(5):1482-1489.

34. Sterrett LE, Schamberger MS, Ebenroth ES, et al: Myocardial perfusion and exercise capacity 12 years after arterial switch surgery for D-transposition of the great arteries. Pediatr Cardiol 2011:32:785-791. 
TABLES:

Table (1): Demographic, clinical, and echocardiographic data of the studied groups.

\begin{tabular}{|c|c|c|c|}
\hline & $\begin{array}{l}\text { Group I (Senning } \\
\text { patients) N: } 31\end{array}$ & $\begin{array}{l}\text { Group II (Controls) } \\
\text { N: } 30\end{array}$ & P-value \\
\hline $\begin{array}{l}\text { Demographic } \\
\text { characteristics: }\end{array}$ & $\begin{array}{l}\text { Demographic } \\
\text { characteristics: }\end{array}$ & $\begin{array}{l}\text { Demographic } \\
\text { characteristics: }\end{array}$ & $\begin{array}{l}\text { Demographic } \\
\text { characteristics: }\end{array}$ \\
\hline $\begin{array}{l}\text { Age at Senning } \\
\text { operation (months) }\end{array}$ & $11.2 \pm 1.30$ & & \\
\hline $\begin{array}{l}\text { Age at examination } \\
\text { (years) }\end{array}$ & $12.88 \pm 3.12$ & $12.50 \pm 2.92$ & 0.08 \\
\hline Weight (kg) & $31.71 \pm 9.17$ & $33.18 \pm 8.96$ & 0.12 \\
\hline Gender: Male Female & $\begin{array}{l}20(62.52 \%) 11(35.48 \\
\%)\end{array}$ & $\begin{array}{l}15(50.00 \%) 15(50.00 \\
\%)\end{array}$ & \\
\hline Clinical data: & Clinical data: & Clinical data: & Clinical data: \\
\hline $\begin{array}{l}\text { Symptoms at } \\
\text { presentation: - None } \\
\text { - Dyspnea - Chest } \\
\text { infection - Arrhythmias }\end{array}$ & $\begin{array}{l}19(61.29 \%) 9(29.03 \\
\%) 3(9.68 \%) 0(0 \%)\end{array}$ & & \\
\hline Hemodynamic data: & Hemodynamic data: & Hemodynamic data: & Hemodynamic data: \\
\hline $\begin{array}{l}\text { Oxygen saturation } \\
(\%)\end{array}$ & $97.75 \pm 0.50$ & $99.15 \pm 0.76$ & $0.04^{*}$ \\
\hline Heart rate (bpm) & $98.45 \pm 15.76$ & $89.31 \pm 10.17$ & $0.01^{*}$ \\
\hline $\begin{array}{l}\text { Blood pressure } \\
(\mathrm{mmHg})\end{array}$ & $\begin{array}{l}105.85 \pm 13.31 / 71.75 \pm \\
11.41\end{array}$ & $\begin{array}{l}107.50 \pm 14.55 / 72.00 \pm \\
10.24\end{array}$ & 0.26 \\
\hline Pro-BNP (ng/L) & $531.54 \pm 45.33$ & $115 \pm 13.62$ & $<0.001^{*}$ \\
\hline $\begin{array}{l}\text { Echocardiographic } \\
\text { data (Rest): }\end{array}$ & $\begin{array}{l}\text { Echocardiographic } \\
\text { data (Rest): }\end{array}$ & $\begin{array}{l}\text { Echocardiographic } \\
\text { data (Rest): }\end{array}$ & $\begin{array}{l}\text { Echocardiographic } \\
\text { data (Rest): }\end{array}$ \\
\hline $\begin{array}{l}\text { Tricuspid regurge } \\
\text { (TR): - Mild - } \\
\text { Moderate - Severe }\end{array}$ & $\begin{array}{l}18(58.06 \%) 9(29.03 \\
\%) 4(12.90 \%)\end{array}$ & & \\
\hline $\begin{array}{l}\text { Baffle dysfunction: - } \\
\text { Baffle leak - Baffle } \\
\text { stenosis }\end{array}$ & $2(6.45 \%) 0(0 \%)$ & & \\
\hline LVOTO & $1(3.23 \%)$ & & \\
\hline Pulmonary valve: & $0(0 \%) 0(0 \%)$ & & \\
\hline $\begin{array}{l}\text { Stenosis (PS) Regurge } \\
(\mathrm{PR})\end{array}$ & & & \\
\hline RV EDV (ml) & $53.95 \pm 10.31$ & $43.63 \pm 3.87$ & $0.002^{*}$ \\
\hline RV ESV (ml) & $32.15 \pm 9.70$ & $26.63 \pm 5.11$ & $0.015^{*}$ \\
\hline $\begin{array}{l}\text { RV EF Simpson's } \\
(\%)\end{array}$ & $40.13 \pm 2.93$ & $53.17 \pm 3.17$ & $<0.001^{*}$ \\
\hline TAPSE (mm) & $13.81 \pm 1.26$ & $17.45 \pm 2.93$ & $<0.001^{*}$ \\
\hline 2D GLS (\%) & $-11.89 \pm 1.31$ & $-22.35 \pm 6.73$ & $<0.001^{*}$ \\
\hline
\end{tabular}

TR: Tricuspid regurge, LVOTO: Left ventricular outflow tract obstruction, PS: Pulmonary valve stenosis, RV EDV: Right ventricular end-diastolic volume, RV ESD: Right ventricular end-systolic volume, RV EF: Right ventricular ejection fraction, TAPSE: Tricuspid annular plane systolic excursion, 2D GLS: Two-dimensional global longitudinal strain. 
Table (2): Dobutamine stress echocardiography and contractile reserve in Senning patients.

\begin{tabular}{|c|c|c|c|}
\hline $\begin{array}{l}\text { Group I (Senning } \\
\text { patients) N: } 31\end{array}$ & $\begin{array}{l}\text { Group I (Senning } \\
\text { patients) N: } 31\end{array}$ & $\begin{array}{l}\text { Group I (Senning } \\
\text { patients) N: } 31\end{array}$ & $\begin{array}{l}\text { Group I (Senning } \\
\text { patients) N: } 31\end{array}$ \\
\hline & Rest & Stress & P-value* \\
\hline Symptoms: & Symptoms: & Symptoms: & Symptoms: \\
\hline Dyspnea & $9(29.03 \%)$ & $17(54.84 \%)$ & $<0.001^{*}$ \\
\hline Arrhythmias & $0(0 \%)$ & $2(6.45 \%)$ & 0.16 \\
\hline Hemodynamic data: & Hemodynamic data: & Hemodynamic data: & Hemodynamic data: \\
\hline $\begin{array}{l}\text { Oxygen saturation } \\
(\%)\end{array}$ & $97.75 \pm 1.50$ & $96.25 \pm 1.41$ & 0.07 \\
\hline Heart rate $(\mathrm{bpm})$ & $98.45 \pm 15.76$ & $121.50 \pm 17.20$ & 0.067 \\
\hline $\begin{array}{l}\text { Blood pressure } \\
(\mathrm{mmHg})\end{array}$ & $\begin{array}{l}106.50 \pm 13.09 / 72.50 \pm \\
10.24\end{array}$ & $\begin{array}{l}132.25 \pm 13.03 / 82.50 \pm \\
12.51\end{array}$ & $0.042^{*}$ \\
\hline $\begin{array}{l}\text { Echocardiographic } \\
\text { data: }\end{array}$ & $\begin{array}{l}\text { Echocardiographic } \\
\text { data: }\end{array}$ & $\begin{array}{l}\text { Echocardiographic } \\
\text { data: }\end{array}$ & $\begin{array}{l}\text { Echocardiographic } \\
\text { data: }\end{array}$ \\
\hline $\begin{array}{l}\text { Tricuspid regurge } \\
\text { (TR): Mild Moderate } \\
\text { Severe }\end{array}$ & $\begin{array}{l}18(58.06 \%) 9(29.03 \\
\%) 4(12.90 \%)\end{array}$ & $\begin{array}{l}11(35.48 \%) 15(48.39 \\
\%) 5(16.13 \%)\end{array}$ & \\
\hline RV EDV (ml) & $53.95 \pm 10.31$ & $50.25 \pm 8.84$ & 0.31 \\
\hline RV ESV (ml) & $32.15 \pm 9.70$ & $30.35 \pm 9.50$ & $0.010^{*}$ \\
\hline $\begin{array}{l}\text { RV EF Simpson's } \\
\text { method \% }\end{array}$ & $40.13 \pm 2.93$ & $42.47 \pm 2.80$ & 0.063 \\
\hline TAPSE (mm) & $13.81 \pm 1.26$ & $15.34 \pm 2.61$ & $0.003^{*}$ \\
\hline 2D GLS (\%) & $-11.89 \pm 1.31$ & $-15.78 \pm 0.93$ & $<0.001^{*}$ \\
\hline
\end{tabular}

TR: Tricuspid regurge, RV EDV: Right ventricular end-diastolic volume, RV ESD: Right ventricular endsystolic volume, RV EF: Right ventricular ejection fraction, TAPSE: Tricuspid annular plane systolic excursion, 2D GLS: Two-dimensional global longitudinal strain.

\section{FIGURE LEGENDS:}

Figure (1): Assessment of right ventricular (RV) function by automated Simpson's monoplane method in a post-Senning 13 years old child post Senning repair. A showed RV EF of $39 \%$ at rest and B showed improved RV EF to $43 \%$ at peak DSE. The improvement in RV EF was less than $5 \%$.

RV: Right ventricular, EF: ejection fraction, DSE: Dobutamine Stress echocardiography, EDV: End-diastolic volume, ESD: End-systolic volume, RA: Right atrium, SRV: Systemic right ventricle, PVB: Pulmonary venous baffle.

Figure (2): Quantitative Assessment of contractile reserve by assessing right ventricular (RV) function using speckle tracking based GLS in an 11 years old child post Senning repair. A showed RV GLS of $-11.2 \%$ at rest and B showed improvement of RV GLS to $-15.6 \%$ at peak DSE. The improvement in RV Speckled based GLS in this patient was $>2 \%(-4.4 \%)$.

RV: Right ventricular, GLS: Global longitudinal strain, DSE: Dobutamine Stress echocardiography, GS: Global strain, RA: Right atrium, SRV: Systemic right ventricle, LV: Left ventricle, PVB: Pulmonary venous baffle. 

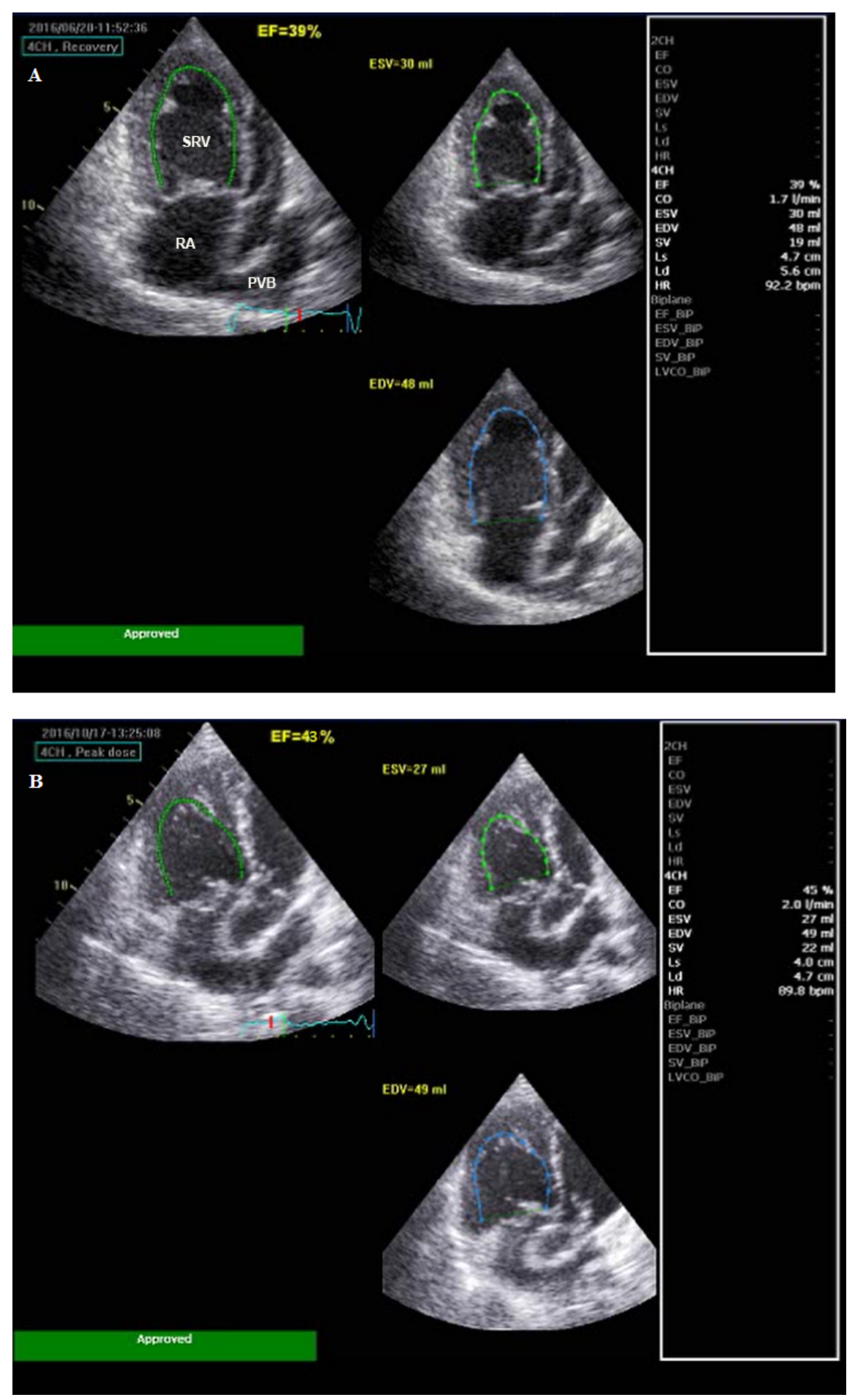

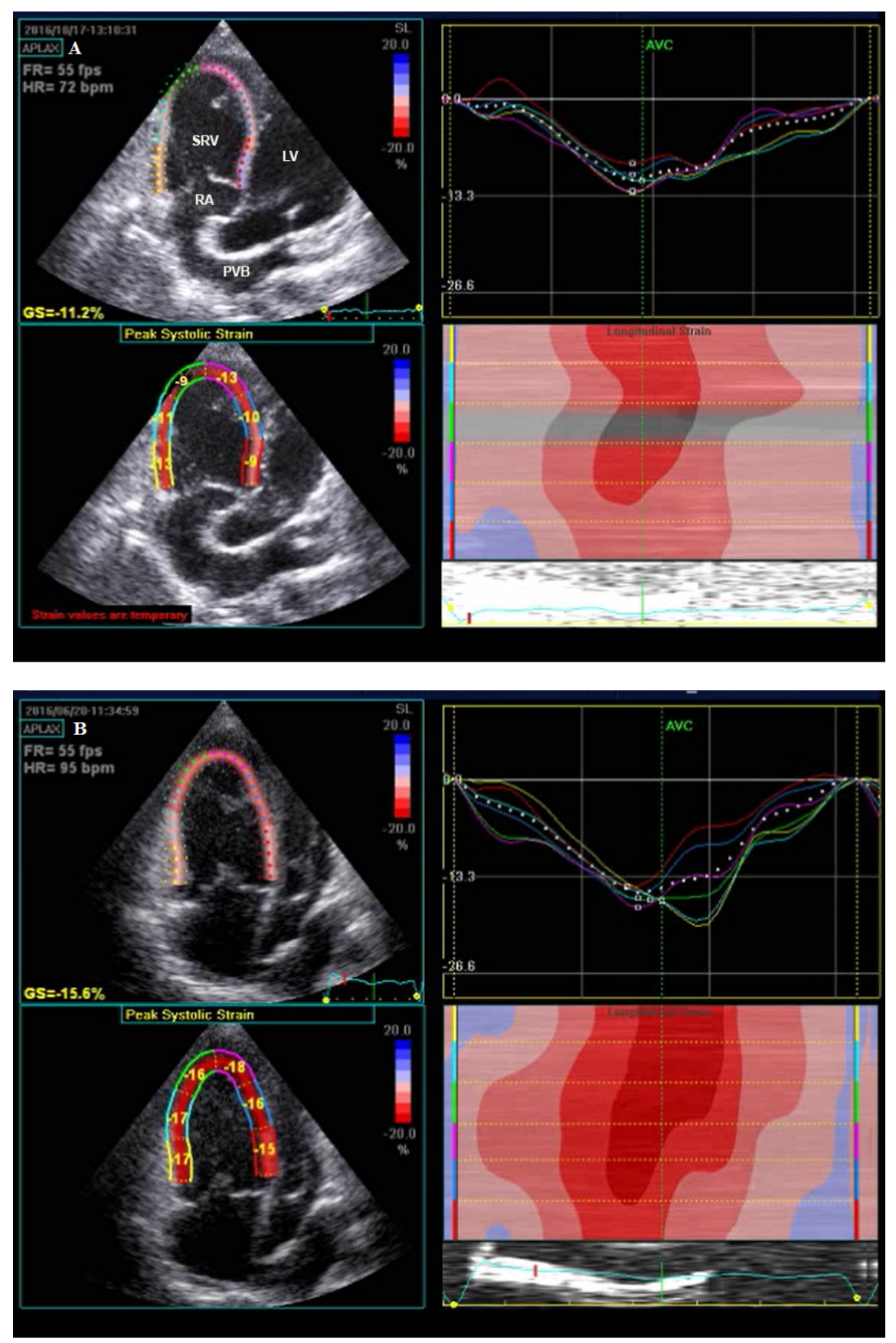